\title{
Soft Coated Wheaten Terrier
}

National Cancer Institute

\section{Source}

National Cancer Institute. Soft Coated Wheaten Terrier. NCI Thesaurus. Code C53732.

The Soft Coated Wheaten Terrier is a medium-sized, compact and squarely proportioned dog. The head is shaped like a rectangle, rather long, with a short, strong muzzle. Jaws are able to seize and grip prey well with large teeth. Puppies are born black, but lighten to the final adult wheaten color by about two years of age. Height: 17-20 inches $(43-51 \mathrm{~cm}$.) Weight: $30-45$ pounds (14-20 kg.) 